\title{
Using of digital tools for the formative assessment of future physics teachers
}

\author{
H. V. Voitkiv, I. M. Lishchynskyy
}

Vasyl Stefanyk Precarpathian National University, Ivano-Frankivsk, Ukraine

Corresponding author. E-mail: h.voitkiv@gmail.com, igor.lishchynskyy@gmail.com

Paper received 15.08.20; Accepted for publication 07.09.20.

https://doi.org/10.31174/SEND-PP2020-236VIII94-17

\begin{abstract}
The article investigates the possibilities of modern digital tools for formative assessment of students of higher educational institutions. It is carried out the classification of digital tools depending on the purpose of formative assessment and it is established three groups: knowledge diagnostics tools, knowledge growth tools, knowledge summary tools. The advantages of using the described digital applications for formational evaluation and methodological aspects of their use are also analyzed and described. The described programs were tested in practice when teaching the course «Modern problems of methods of teaching physics».

Keywords: digital applications, feedback, future physics teachers, testing, formative evaluation.
\end{abstract}

Introduction. Comprehensive diagnosis of knowledge, skills and abilities of students is an integral part of the educational process. According to the normative documents, the assessment of learning outcomes is carried out on the basis of current and final control of knowledge.

Competence orientation of the educational process requires from the assessment process not only the statement of the fact of knowledge, but also the analysis of gaps in knowledge, in order to further eliminate them, the selection of methods, tools, technologies. Therefore, «today it is important to turn current control into formative assessment, which includes current control, but with a more effective response to learning, helps to establish full feedback between teacher and student, the formation of students' learning skills and general culture of teacher assessment» $[1,3]$. However, it is difficult to get good feedback and get a general idea of the learning process, in order to correct it, using traditional methods of current control (for example, tests, oral interviews) within the disciplines, because it requires significant time, both for the development of tasks and for further analysis of survey results. Modern digital tools are an alternative to traditional tools for assessment.

Brief overview of related publications. In the scientific literature there are works which give a description of tools for assessment, areas of their use, ways to use the tool for teaching and learning $[1,3,7,8]$. The following are devoted to the issues of assessment of academic achievements in general and in higher education, in particular: N. Morse (theory and practice of formative assessment in higher school), O. Lokshina (assessment in general secondary education), I. Fishman (theory and practice of formative assessment), B. Bloom (taxonomy of educational purposes). The use of digital tools for formative assessment has been studied by J.Wilmut, N. Morse, M. Gladun and others. Researchers show that «the integration of digital technologies in the educational process of educational institutions is becoming a necessity, and affects the improvement of assessment methods, the use of which has a positive effect on students' knowledge and skills» $[3,5]$.

Appreciating the work of scientists, it should be noted that the use of digital tools with detailed methodological support and explanation for the assessment directly and the formation of experience in using these applications in future teachers, was not carried out.

The aim of the study. The purpose of this work is to consider the methodological aspect of digital tools use to work with students in high school, on the example of the course «Modern problems of methods of teaching physics».

Materials and methods. To achieve the article goal, theoretical and empirical research methods were used: analysis - to study psychological and pedagogical, scientific and methodological research, regulations in the field of education on the use of digital tools for the formative assessment of students of higher pedagogical educational institutions; the available digital applications and their possibilities for conducting formative assessment are analyzed; synthesis - to establish the most optimal applications that can be used in the learning process; observation of the educational process in order to determine and formulate the methodological features of the use of existing applications.

Results and its discussion. Scientific and technological progress, the emergence of digital teaching aids and the competence orientation of the educational process make some adjustments in the process of diagnosing learning outcomes in higher education. If traditional pedagogy distinguishes between final and current assessment, today we must learn to work with summative and formative assessments. If the final and current assessment mainly record the result, the concept of formative assessment is to assess the progress of the learning process to help improve the result. Many authors consider formative assessment as a component of the learning process in which students have the opportunity to look at known truths from the other side, test their knowledge to determine their own progress in the topic, see the error and be able to analyze it. That is, it is an assessment for further learning, for successful learning. N. Morse says that «the application of formative assessment technologies provides feedback that will allow to achieve improvement, and on both sides: and on the part of the teacher - how he should change the design of the educational process: what changes he needs to make in teaching, methods or technologies he uses; and on the part of the student - with which educational tasks he coped successfully, and on the implementation of which he needs to work further» [3]. French scientists note that the key mission of formative assessment in learning is to help the student learn [4].

What is important today is not the evaluation of performance, but the ability to monitor progress, evaluation with an effective response to learning with a purpose. By 
formative assessment, we mean the collection of information about student performance that is used to improve their learning and our teaching. Formative assessment today, according to research, is the most powerful factor in strengthening the understanding of educational material and awareness of learning. Effective formative assessment is based on three issues [3]:

- What does the teacher want to teach students?

- What do students know at the moment? (Where are they now?)

- How can learning be improved? That is, how do we bridge the gap between desired learning goals and current student understanding.

The answer to the first question of formative assessment is given by: effectively formulated learning objectives, acquaintance of students with the course program, acquaintance with samples of the best learning outcomes (projects or answers) obtained by students who have already completed the course.

The most effective ways (by D. Wiliam) that answer the second question of formative assessment, are:

- conversation with students to get information about the understanding of the submitted material;

- effective responses of the teacher to the student's response with the identification of ways to further avoid mistakes;

- teaching students self-assessment and collective assessment, possession the student's of information, which should be a successful learning outcome and monitoring with analysis and progress of their own current results;

- separation of assessment and response (when communicating assessment in the current assessment, all attention is focused on assessment, which prevents further reaction to effective response; the reaction should stimulate thinking growth, so you should focus on the most important areas and techniques that students can use for this) $[4,5]$

The teacher's task in formative assessment is a clear formulation of learning outcomes that need to be achieved and that will be assessed; stimulate the growth of thinking through effective feedback in the evaluation process; to make a student a participant in educational and evaluation activities. To implement them, it is necessary to: constantly provide feedback, providing students with comments, remarks, advice on their activities; change teaching methods and technologies depending on changes in students' learning outcomes.

Student's task: learn to learn, to analyze their activities, to focus on the learning process, to use feedback for their growth and gain experience for their professional activities. Execution of these tasks is possible under the condition of active involvement in training and organization of the process of own training.

Known applications for evaluation today are: AnswerGarden, Google Forms, GoSoapBox, Kahhot, Plickers, Socrative, Quizizz, Weebly, Teded, Quizlet, Quizizz, Triventy, Strawpoll.Me, Wordart, Tagxedo, Word.Pro, Mentimeter, Poll Ewerywhere. Diagnosis by digital means and technologies not only saves the time of the teacher and the student, but also provides a clear presentation of the results, which allows to make an effective response to the teacher and be a convenient tool for the student to analyze personal growth in academic work.
Conducting formative assessment at different stages of learning may have different purposes. Thus, before starting work on the topic - the survey is conducted in order to identify existing knowledge, orientation in the topic, activation of attention - this is the diagnostic stage of formative assessment. It is useful for both the teacher to design further work and students to get a general idea of what needs to be studied. In the learning process - the survey is conducted to identify gaps - this is the formative stage of assessment. At the end of the study of the topic, section, course of the survey is conducted for the purpose of generalization, summarizing, repetition - the final stage of evaluation.

After analyzing the capabilities of the above digital tools and testing them, we determined that any of the applications is suitable for the implementation of the diagnostic stage of formative evaluation. However, in the process of working with students, we saw that they feel freer in their answers and are more involved in the work when they are sure that they will not be evaluated. Therefore, the first group of digital applications, which we will call the diagnostic group, includes those that do not identify students and give a good visual result of the processed answers, which we will use in the work for analysis. Such applications are: Answer Garden, Wordart.com, Taghedo.com, Word.pro, Mentimeter, etc. These applications are characterized by a minimalist and clear design. They record short answers from your respondents and present the opinion of all participants in the form of an associative cloud of opinions, or in the form of a diagram, depending on the format of the questions (open answer, choice tests), which allows the teacher to understand students' orientation in subject and present correctly curriculum and formulate goals.

We think, that the positive point of using these tools at this stage is the nuance that in the results of surveys processed by the programs, you can see the number of participants, the prevailing opinion, but not the results of each, which hinders biased teacher's judgment. The process of self-assessment, motivation and goal setting in students is intensified, who have the opportunity to see their orientation in the topic and compare it with the learning outcomes they have to achieve [6].

Consider this on the example of studying the discipline «Modern problems of methods of teaching physics and astronomy», by students majoring in Secondary education (physics). It is worth noting that the course of general physics has already been completed by students. For example, before studying the topic «Regulatory support for teaching physics at school» you can ask the question:

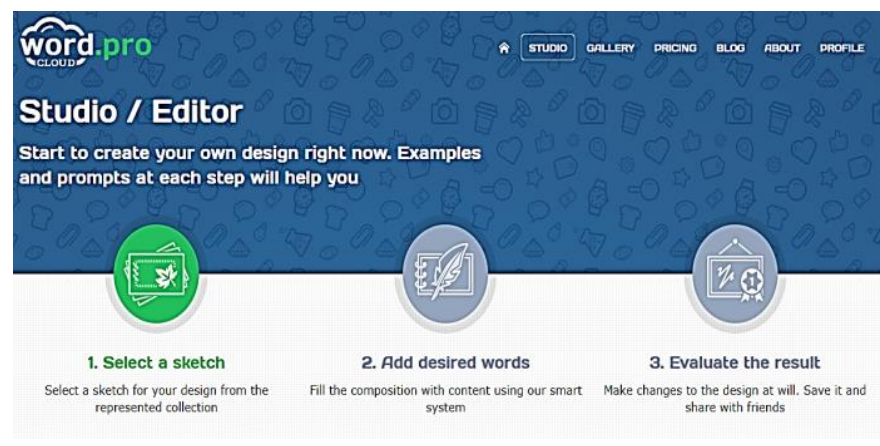

Image 1. Word.pro application interface. 
«What do you know the normative educational documents that are needed for the quality organization of the educational process of a physics teacher?» Image 1. presents the interface of the tools, which appears in the teacher, after passing the authorization on the example of the application Word.pro.

Students respond anonymously from their smartphones by connecting to the link provided by the teacher. The result of processing the answers is presented in Image 2 .

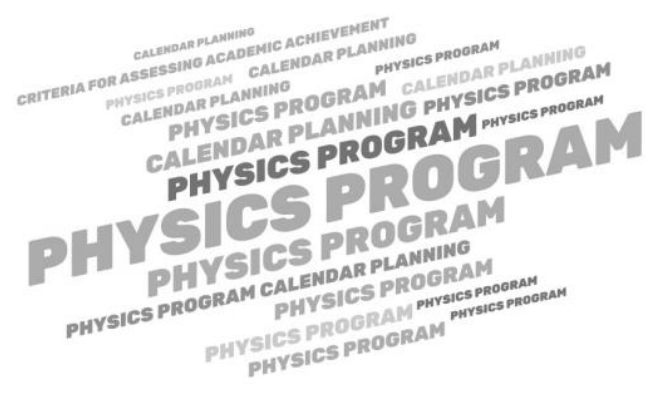

Image 2. The result of the processed answers in the application Word.pro.

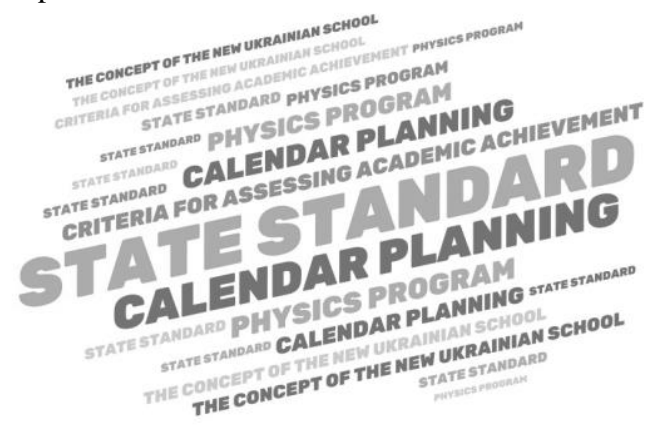

Image 3. Visualization of the basic concepts of the topic by the teacher in the application Word.pro.

In Image 3, as a example, presents a cloud of basic concepts of the course module. This visualization will give the student the opportunity to see where he is now and what he should come to.

To ensure the use of this group applications, students need smartphones and a multimedia board to present and analyze the results. It is worth noting that all the information on the surveys is stored in the teacher's office, and the results - «Clouds» of answers can be disseminated among respondents.

Applications that allow you to track student progress growth applications - to answer the second question of formative assessment, include Mentimeter, Socrative, Poll Ewerewhere, Plickers, Kahoot, Google Forms. Due to the similarity of functions on the interface, we will describe in more detail the capabilities of Mentimeter when teaching the course. With these tools, we have the opportunity to engage our audience in the survey in real time, and visual presentation of the results turns one-sided presentation of the material into two-way conversations with the audience, which is important to ensure effective response, inclusion in learning, activation. Work with the program is carried out in three steps:

- $\quad$ asking a question: use multiple choice questions to identify gaps in comprehension, or start group discussions with a colored word cloud;

- answer collection: students send answers by visiting a website from their mobile device or by sending a message to a number;

visualization of instant results: answers are displayed in an animated graph or chart built into your presentation, the results are updated live for everyone to see.

It is worth noting that the program shows the audience the results of joint responses of all participants, but at the same time, there is a function of disseminating individual results to each student. Working with these applications requires smartphones and a screen to present and discuss the results. The interface of the teacher's office is presented in Image 4.

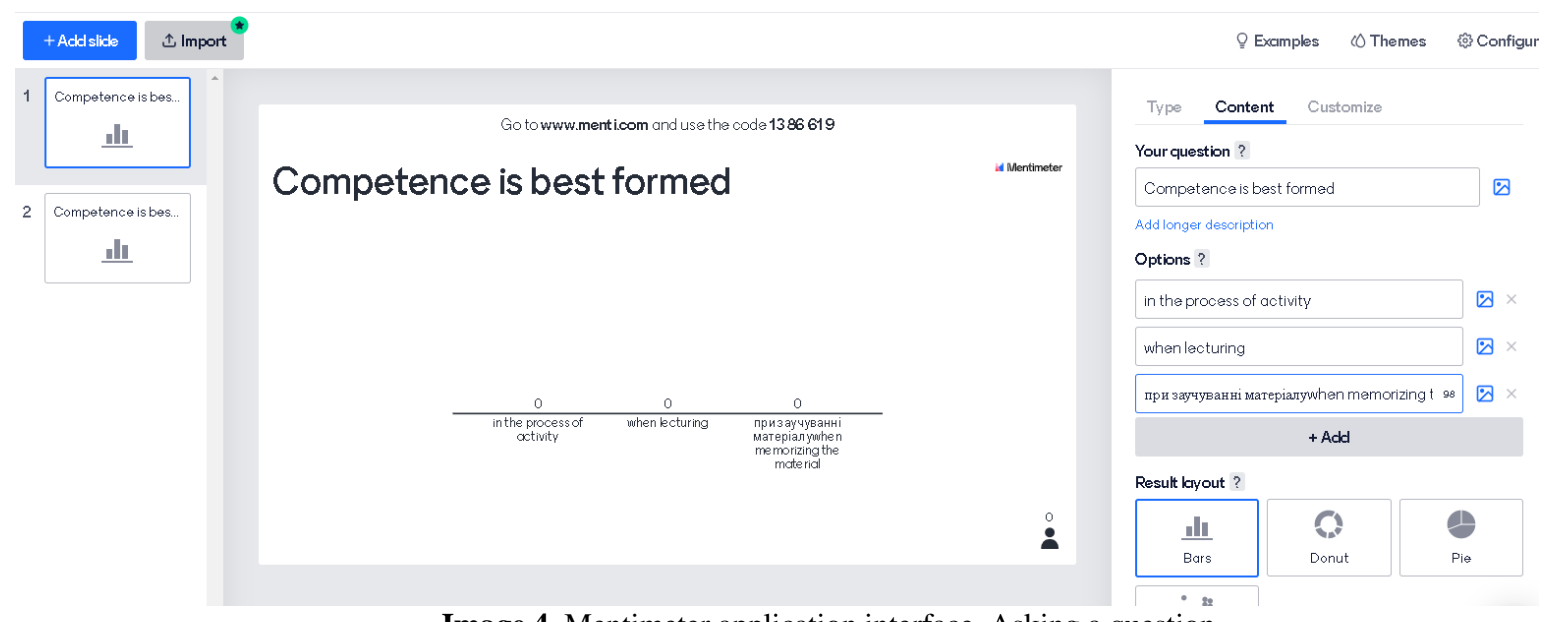

Image 4. Mentimeter application interface. Asking a question.

All applications in this group require mobile devices to record respondents' responses, except for the Plickers tool, which allows field-based assessment data to be collected without students having to use technical devices or even paper and pencil. As a control notebook use cards plickers (Image 5), four sides of which correspond to four possible answers. 


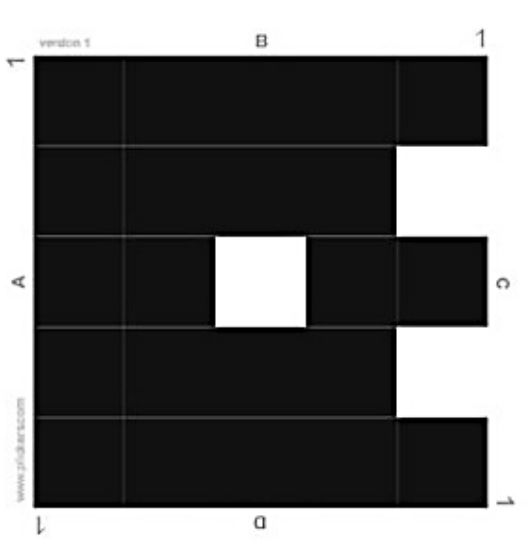

Image 5. Standard view of survey cards.
The teacher collects students' answers by installing an application from the Play Market application on their own mobile device and selecting the menu item - «scan answers». And the results of studies are stored in the teacher's office. They can also be instantly presented on the screen for discussion, or sent individually for introspection to each student. Among this group of applications, the previous creation of a class with the entry of data on respondents requires applications Plickers and Google Forms, in all others, students are authorized to enter their own name. Image 6 shows a demonstration of the question from the teacher's office, where in the upper left corner it is indicated who will be interviewed.

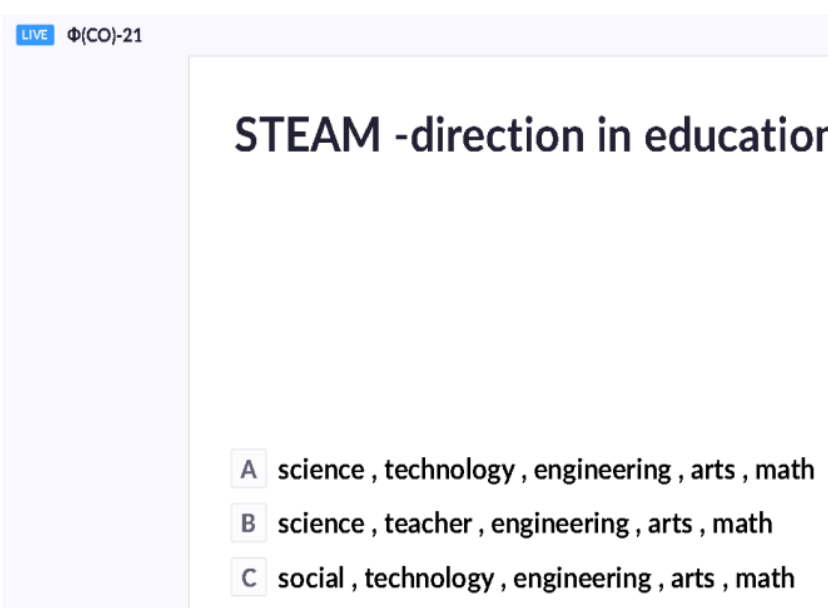

Image 6. Demonstration of the question from the teacher's office in the Plickers application.

For the final stage of formative assessment, as practice has shown, the most convenient applications are applications in which the teacher identifies respondents, ie those in which you can create a class in advance and enter names according to the class journal. These include Google Forms and Plickers. This group of applications is called - tools for generalizing knowledge. It is worth noting that the programs Mentimeter, Kahhot, Plickers, Poll Ewerewhrere have the function of importing readymade questions.

Conclusions. Thus, to ensure the formation of competencies in students, it is important to formative assessment in the educational process of higher education. Digital applications are effective tools for conducting formative assessment. We classified digital applications depending on the purpose of conducting formative assessment into three groups: knowledge diagnostic tools; knowledge growth tools; knowledge summary tools. The advantages of using digital tools over traditional assessment tools are time savings, visual presentation of survey results and instant feedback. Examples of their use in high school on the example of the course «Modern problems of methods of teaching physics» are given. The practice of formative assessment in higher education, when working with future teachers, it pursues two goals: to effectively assess students on the basis of a competency-based approach and to demonstrate to them the experience of implementing formative assessment, which is undoubtedly important for their work in general secondary education.

\section{REFERENCES}

1. Kaban L.V. Formative assessment of students' academic achievements in the new Ukrainian school // Public education. Electronic scientific professional publication, 2017. $1(31)$.

2. Cowie B. A Mode of Formative Assessment in Science Education / Bronwen Cowie, Beverly Bell //Assessment in Education: Principles, Policy and Practice. - 1999. - Vol. 6, n. 1 (1 March).- P. 101-116.

3. Morse N. V, Barna O.V, Wember V.P. Formative assessment: from theory to practice // Informatics and information technologies in educational institutions, 2013. - № 6. - P. 45-57

4. Lokshina O.I. The content of school education in the countries of the European Union: theory and practice (second half of the XX - beginning of the XXI century): monograph / O.I.
Lokshina O.I. - K.: Bogdanova AM, 2009. - 404 p.

5. Wilmut J. Assessment for learning: textbook. way. (Master class, Kyiv, 2007).

6. Morze N., Gladun M., Wember V., Dziabenko O.. Methodological and technical design of innovative classroom. Modernization of Pedagogical Higher Education by Innovative Teaching Instruments (MoPED), 2018. - $130 \mathrm{p}$.

7. Vember, V. Implementation of BYOD technology for formative assessment. Innovative technologies in education: a collection of materials of the international scientific and technical conference. Ivano-Frankivsk, 2019. - 45-47.

8. Test technologies for assessing the competencies of students: a guide / ed.Lyashenko O.I, Zhuk Yu. O. - K.: Pedagogical thought, 2015. - 181 p.9. 